\title{
Viscero-somatic and viscero-visceral reflexes in brain death
}

\author{
FABRIZIO CONCI, FRANCESCO PROCACCIO, MASSIMO AROSIO, \\ LUIGI BOSELLI
}

From IV Servizio di Anestesia e Rianimazione, O. Niguarda Ca' Granda, Milano, Italy

SUMMARY Little is known about spinal visceral reflexes in brain-dead man, although they have been described in experimental animals. In 1983, 25 brain-dead individuals were observed during donor nephrectomy. It was confirmed that some of these donors, without higher centre modulation and not under significant pharmacological influence, had viscero-somatic motor reflexes and viscerovisceral cardiovascular reflexes.

It is well accepted that in brain-death, after an initial period of spinal shock, cutaneous and stretch reflexes can still be present or can reappear. ${ }^{1-3}$ The appearance of limited autonomic regulation of temperature or blood pressure has been described. ${ }^{45}$ In addition, certain autonomic reflexes sometimes may survive the cessation of all circulation above segments $\mathrm{Cl}-\mathrm{C} 4,{ }^{6}$ so that an increase of the pressure in the urinary bladder might cause a blood pressure increase. ${ }^{3}$ Spinal viscero-somatic motor reflexes and spinal viscerovisceral cardiovascular reflexes have been demonstrated in decapitated animals. In these animals some surgical procedures in the abdominal cavity can produce contractions of leg and belly muscles and raise the blood pressure. ${ }^{7}$

To our knowledge, there are no reports in the literature of visceral reflexes induced in brain-dead man during kidney removal for transplantation. We wished to see whether or not brain-dead man has spinal visceral reflexes that can be elicited from the abdominal cavity.

\section{Patients and methods}

In 1983 twenty-five patients were donors for kidney transplants after brain death. Nine of them had subarachnoid haemorrhages and sixteen had head injuries. The ages of the patients were 17-61 years with an average of $32 \pm \cdot 2 \cdot 8$ (mean $\pm S E$ ). There were fourteen men and eleven women (table 1 ).

Address for reprint requests: Dr Fabrizio Conci, IV Servizio di Anestesia e Rianimazione, O. Niguarda $\mathrm{Ca}^{\prime}$ Granda-P.zza Osp. Maggiore 3, Milano, Italy.

Received 25 September 1984 and in final revised form 17 June 1985. Accepted 24 June 1985
All of them fulfilled the Italian legal criteria for brain death. These include no brain stem reflexes, apnoea for more than two minutes and muscular atony, all verified every hour for 12 hours. In addition, isoelectric EEG must be recorded for one half hour every 4 hours during the 12-hour observation time and there must not be any hypothermia or drug-induced depression. Nephrectomy was carried out immediately after the diagnosis of brain death. The average time on the ventilator before diagnosis was $28 \pm 4$ hours (mean \pm SE) including the legal observation time of 12 hours. All patients were infused with saline solution to maintain good central venous pressure during the observation time and the surgical operation. Thirteen patients required dopamine (Revivan, Simes), IV drip at $10 \mu \mathrm{g} / \mathrm{kg} / \mathrm{min}$ or more during the observation time and/or surgical operation to maintain the blood pressure above $90 \mathrm{~mm} \mathrm{Hg}$ (table 1$){ }^{8}$ Ten patients who had polyuria of more than $1 \mathrm{l} / \mathrm{h}$ were given $1 \mu \mathrm{g}$ desmopressin (Minirin-DDAVP, Valeas), a long acting synthetic antidiuretic hormone with low pressor effect ${ }^{9}$ intravenously during the observation period (table 1). Desmopressin was never given during the nephrectomy itself. During the operation heart rate and intra-arterial blood pressure were monitored continuously. The data were analysed statistically with the $\chi^{2}$ test and the Student $t$ test.

\section{Results}

No patients had marked reflex responses at the beginning of the operation, during incision of the skin or muscle. Fifteen patients $(60 \%)$ had contraction of abdominal musculature after the parietal peritoneum was cut and an IV bolus of $4 \mathrm{mg}$ pancuronium bromide (Pavulon, Organon) was needed to obtain relaxation. ${ }^{8}$ Six of the fifteen patients with viscero-somatic motor reflexes after peritoneal cutting had been given dopamine and seven desmopressin (tables 1, 3). The 
Table 1 Clinical details, viscero-somatic motor reflexes and viscero-visceral cardiovascular reflexes of 25 consecutive brain-dead kidney donors

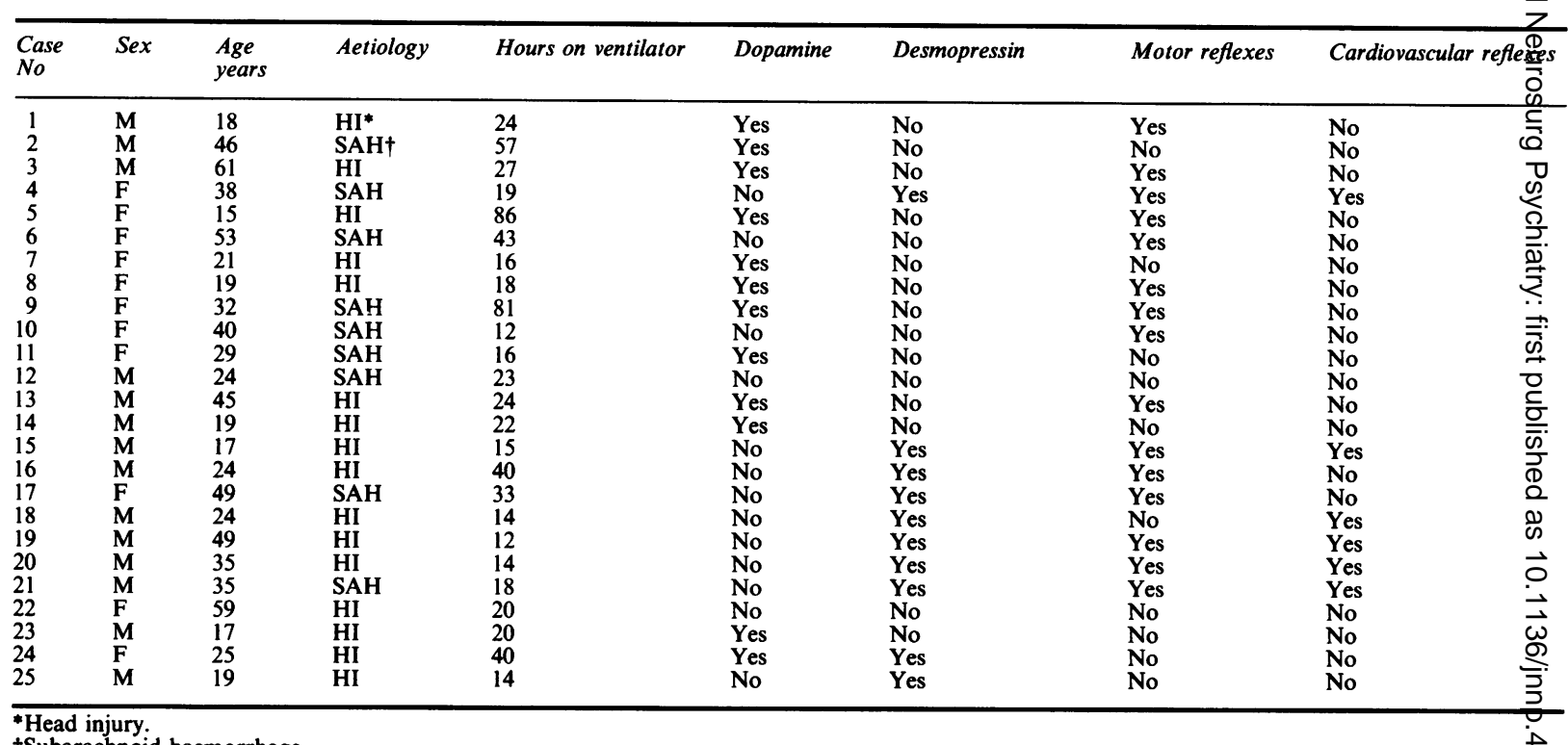

†Subarachnoid haemorrhage.

age of these patients and the time on the ventilator was $35.3 \pm 3.7$ years (mean $\pm S E$ ) and $31 \pm 6$ hours (mean \pm SE), the longest time being $86 \mathrm{~h}$. The means \pm SE of patients without motor reflexes were respectively $28 \pm 4 \cdot 3 \mathrm{yr}$ and $24 \cdot 2 \pm 4.3 \mathrm{~h}$. Six patients $(24 \%)$ had a total of thirteen sudden variations in cardiovascular parameters after various surgical stimuli (table 2). All of these patients had blood pressure of over $90 \mathrm{~mm} \mathrm{Hg}$ without dopamine. The rises in heart rate and blood pressure were always related to the application of a specific surgical stimulus and vanished immediately after it was stopped. The variation $\stackrel{\circ}{\circ}$ o was particularly evident in systolic blood pressure, $\stackrel{\mathbb{Q}}{\Omega}$ 의 which increased by 20 to $80 \mathrm{~mm} \mathrm{Hg}$ with an average $\vec{\circ}$ of $38.8 \pm 4$ (mean $\pm \mathrm{SE}$ ). Changes in heart rate, when present, were synchronous with changes in blood 0 pressure. The diastolic blood pressure was modified $\stackrel{\overrightarrow{0}}{\overrightarrow{0}}$

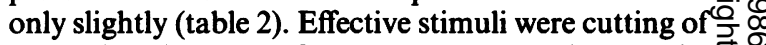
parietal peritoneum (five responses), traction on the larger arterial vessels, such as the aorta, renal arteries

Table 2 Viscero-visceral cardiovascular reflexes in brain dead kidney donors. Systolic (SBP) and diastolic (DBP) blood pressures ( $\mathrm{mm} \mathrm{Hg}$ ) and heart rate (HR) before and after specific surgical stimuli

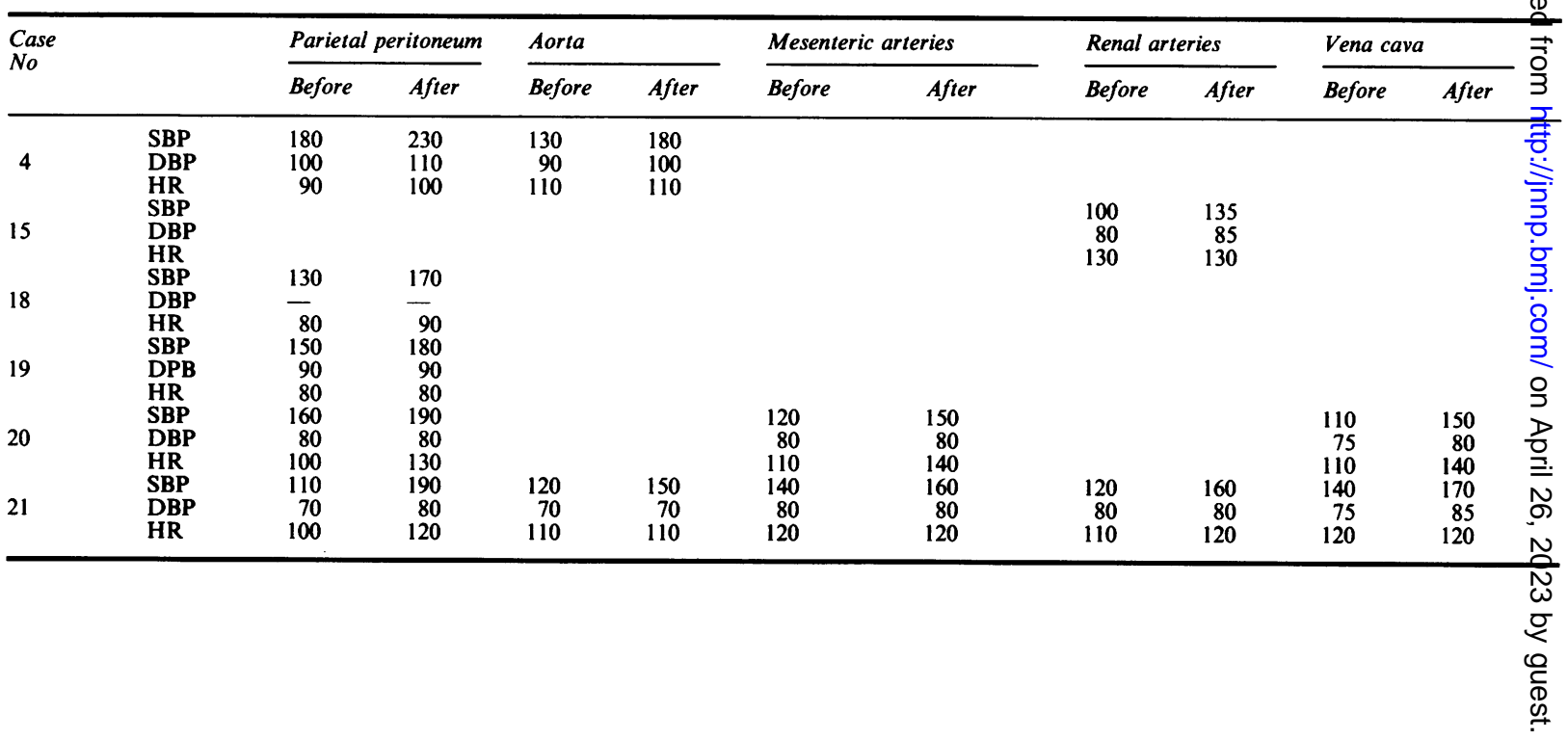


Table 3 Relation between aetiology of brain death, time on ventilator, administration of drugs and presence of viscero-somatic motor reflexes and viscero-visceral cardiovascular reflexes in 25 brain dead kidney donors

\begin{tabular}{|c|c|c|c|c|}
\hline & \multicolumn{2}{|c|}{ Motor reflexes } & \multicolumn{2}{|c|}{ Cardiovascular reflexes } \\
\hline & Yes & No & Yes & No \\
\hline \multirow{4}{*}{$\begin{array}{l}\text { Total patients } \\
\text { Head injury } \\
\text { Subarachnoid haemorrhage } \\
\text { Time on ventilator in hours (mean } \pm \text { SE) }\end{array}$} & 15 & 10 & \multirow{9}{*}{$\begin{array}{l}6 \\
4 \\
2 \\
15 \cdot 3 \pm 3 \cdot 1 \ddagger \\
0^{*} \\
6 \\
6 \dagger \\
0 \\
5 \\
6\end{array}$} & \multirow{9}{*}{$\begin{array}{l}19 \\
12 \\
7 \\
32 \cdot 3 \pm 3 \cdot 5 \\
12 \\
7 \\
4 \\
15 \\
10 \\
-\end{array}$} \\
\hline & 9 & 7 & & \\
\hline & & 3 & & \\
\hline & $31 \pm 6$ & $24 \pm 4 \cdot 3$ & & \\
\hline $\begin{array}{l}\text { Dopamine yes } \\
\text { no }\end{array}$ & $\begin{array}{l}6 \\
9\end{array}$ & $\begin{array}{l}6 \\
4\end{array}$ & & \\
\hline Desmonressin yes & 7 & 3 & & \\
\hline Desmopressin $\begin{array}{l}\text { ycs } \\
\text { no }\end{array}$ & 8 & 7 & & \\
\hline Motor reflexes & 15 & - & & \\
\hline Cardiovascular reflexes & 5 & 1 & & \\
\hline
\end{tabular}

${ }^{*} \mathrm{p}<0.02$ at $\chi^{2}$ test: interaction between cardiovascular reflexes and dopamine.

$t \mathrm{p}<0.002$ at $\chi^{2}$ test: interaction between cardiovascular reflexes and desmopressin.

$\pm \mathrm{p}<0.01$ at Student $t$ test: group of patients with cardiovascular reflexes compared with group without cardiovascular reflexes.

and mesenteric arteries (six responses), traction on the inferior vena cava (two responses) (table 2). Although none of the six patients with viscero-visceral cardiovascular reflexes (CVR) had been given dopamine, all had been given desmopressin (table 1,3 ). The age of these patients was $33 \pm 4.5 \mathrm{yr}$ (mean \pm SE) and the time on ventilator was $15.3 \pm 1 \mathrm{~h}$ (mean $\pm \mathrm{SE}$ ). The means \pm SE of patients without cardiovascular reflexes were respectively $32.3 \pm 3.5$ yr and $32.4 \pm 4.8$ $\mathrm{h}$ with the longest time on ventilator being $19 \mathrm{~h}$.

Fluctuations in heart rate and blood pressure immediately after complete ligation of blood vessels were minimal or absent. No reflexes were elicited by intestinal manipulation. Motor reflexes were not influenced by the age and the time on ventilator. Cardiovascular reflexes were not influenced by the age but seemed to be influenced by the time on ventilator ( $p<$ 0.01 at Student $t$ test) (table 3).

Sex and aetiology also did not seem to influence the presence or absence of motor reflexes and cardiovascular reflexes $\left(\chi^{2}\right.$ test) (table 3$)$. Dopamine and desmopressin administration did not influence the occurrence of motor reflexes, but did influence the occurrence of cardiovascular reflexes ( $p<0.02$ for dopamine and $\mathrm{p}<0.002$ for desmopressin at $\chi^{2}$ test) (table 3). Five of fifteen patients with motor reflexes had also cardiovascular reflexes. Five of six patients with cardiovascular reflexes had also motor reflexes (table 3).

\section{Discussion}

Our clinical observation of 25 brain-dead kidney donors during the surgical removal of the kidneys showed that some of them had viscero-somatic and viscero-visceral reflexes. Our observations are in agreement with the observation that spinal reflexes are maintained after brain death ${ }^{\mathbf{1 - 3}}$ whenever the ischaemic lesion has stopped above spinal cord seg- ments $\mathrm{Cl}-\mathrm{C} 4 .^{6}$ Little is known about autonomic activity in brain-dead man. ${ }^{3-5}$

Spinal viscero-somatic motor reflexes and viscerovisceral cardiovascular reflexes have been described in experimental animals. Different types of stimuli in the abdominal cavity produce reflex responses in the abdominal musculature and changes in heart rate and blood pressure. ${ }^{7}$ Directly stimulated parietal peritoneum and splanchnic nerves were particularly reactive to manipulation, while mesenteric loops were not.

In brain-dead man too, we found that the parietal peritoneum was very reactive in producing motor reflexes and cardiovascular reflexes, while manipulation of mesenteric ansae was not. The surgical manipulation of the blood vessels surrounded by their nerve plexes caused active cardiovascular reflexes. Obviously motor reflexes will not be seen at this stage of the operation if the patients had been previously curarised.

Our observation was limited to the normal surgical stimulation of cutting and mechanical traction and did not include any study of changes in vascular flow due to surgical ligation.

We did not record stretch reflexes during the surgical procedure or during the legal observation time and therefore do not know whether they occurred.

Motor reflexes were seen in $60 \%$ of all patients, cardiovascular reflexes was observed in only $24 \%$, and five of six patiens with cardiovascular reflexes also had motor reflexes (table 3). Age, sex and aetiology of the brain death did not seem significantly to influence the occurrence of motor reflexes and cardiovascular reflexes.

Patients with cardiovascular reflexes had spent less time on the ventilator. The administration of dopamine and desmopressin were not related to motor reflexes, while cardiovascular reflexes seemed to be related to the giving of desmopressin and not having given dopamine (table 3). Cardiovascular reflexes 
were observed in well-maintained patients, who had spent less time on the respirator, and who had good spontaneous control of circulation without dopamine, and good volume maintenance with desmopressin.

Desmopressin, given early during the observation period and never during the operation, contributed to good volaemic equilibrium by inhibition of excess diuresis; it had no detectable vasoactive effect at the low doses used. ${ }^{9}$

In conclusion, these results indicate that man without higher centre modulation and free of significant pharmacological effects can still have viscero-somatic motor reflexes and viscero-visceral cardiovascular reflexes. Further work is in progress to gain deeper insight into the mechanisms of these phenomena.

\section{References}

${ }^{1}$ Ivan LP. Spinal reflexes in cerebral death. Neurology (Min- neap) 1973;23:650-2.

2 Jørgensen EO. Spinal man after brain death. Acta Neurochir (Wein) 1973;28:259-73.

${ }^{3}$ Ingvar DH. Brain death-total brain infarction. Acta Anaesth Scand suppl 1971;45:129-40.

${ }^{4}$ Ibe K. Clinical and pathophysiological aspects of the iriravital brain death. Electroencephalogr Clin Neurophysiol 1971;30:272.

${ }^{5}$ Lücking CH, Gerstenbrand F. The clinical picture of brain death after serious brain injuries. Electroencephalogr Clin Neurophysiol 1971;30:272.

${ }^{6}$ Schneider H, Matakas F. Pathological changes of the spinal cord after brain death. Acta Neuropathol 1971;18:234-47.

${ }^{7}$ Downman CBB, McSwiney BA. Reflexes elicited by visceral stimulation in the acute spinal animal. $J$ Physiol (Lond) 1946;105:80-94.

${ }^{8}$ Luksza AR. Brain-dead kidney donor: selection, care, and administration. Br Med J 1979;1:1316-9.

${ }^{9}$ Martindale W. The Extra Pharmacopoeia 28th ed. London: The Pharmaceutical Press: 1982. 